\title{
Rezension zu: Philip Matyszak, Geschichte der Römischen Republik. Von Romulus zu Augustus (2004)
}

\author{
Marion Boos
}

Das Buch „Geschichte der Römischen Republik“ von Philip Matyszak behandelt die römische Geschichte, wie der Titelzusatz erklärt, von dem legendären Stadtgründer Romulus bis hin zu Augustus, dem ersten Kaiser des Imperiums. Dargestellt wird sie anhand von 57 Einzelbiographien bedeutender römischer Staatsmänner und Feldherren, die in chronologischer Reihe aufeinander folgen. Zahlreiche, z.T. farbige Abbildungen und anschauliche Karten illustrieren das Werk und machen es $\mathrm{zu}$ einer besonders für den Laien leicht verdaulichen Kost. Themenkästen behandeln schlaglichtartig einzelne Aspekte der römischen Kultur und Gesellschaft.

Der Umfang des Werkes läßt es nicht zu, die übersichtlichen, jedoch entsprechend dem Ziel der Arbeit kurz gefaßten Biographien einzeln zu besprechen. Stattdessen soll im folgenden eine zusammenfassende Besprechung geliefert werden. Nach einer Einführung zu Aufstieg und Ausdehnung des Römischen Reiches bis zum Ende der Republik $(6-11)$ sowie einer knappen Beschreibung der wichtigsten literarischen Quellen (12/13) folgt ein Kapitel über das Zeitalter der Könige (14 - 45). Dieses Zeitalter läßt der Autor mit dem vielen aus der Schulzeit bekannten Jahr $753 \mathrm{v}$. Chr. beginnen, verknüpft mit der Biographie der sagenhaften Zwillinge Romulus und Remus. Daß es sich bei diesen Figuren nicht um historisch gesicherte Personen handelt, wird m.E. von M. nicht deutlich genug herausgestellt. Auch bei den Darstellungen der folgenden Könige, Numa Pompilius (22 - 25), Tullus Hostilius (26 - 30) und Ancus Marcius (30/31) verwirrt der Historiker den Leser, indem er diese legendären Gestalten wie historische behandelt und dabei oftmals nur am Rande erwähnt, daß die Existenz dieser Personen zweifelhaft bis unwahrscheinlich ist. Gerade weil das ansonsten sehr klar aufgebaute und verständliche Werk in besonderem Maße ein interessiertes Laienpublikum ansprechen soll, hätte in diesem Punkt eine deutlichere Trennung zwischen Fakten und Vermutungen gezogen werden müssen. Dennoch ist es erfreulich, die frühen Könige Roms in einer klaren Übersicht vorgestellt zu bekommen.

Auch das Jahr 753 v. Chr. ist problematisch. Während die Sage von der Gründung der Stadt durch Romulus und der Raub der Sabinerinnen, anschaulich gemacht durch ein Historiengemälde Jacques-Louis Davids von 1799, den Hauptstrang in M.s Darstellung bilden, verweist er lediglich in einem kleinen Themenkasten (19) auf die bereits in das 10. Jh. v. Chr. zurückgehenden frühesten Gräber auf dem Palatin ${ }^{1}$.

Den letzten Abschnitt der Königszeit bilden die Biographien der drei etruskischen Könige Tarquinius Priscus (32 - 37), Servius Tullius (37 - 39) und Tarquinius Superbus $(40-42)$ sowie die des berühmten L. Iunius Brutus, des sagenhaften Begründers der römischen Republik (43 - 45). Zur näheren Erläuterung der etruskischen Kultur fügt M. einen besonderen Abschnitt über das etruskische Volk ein $(34 / 35)$.

\footnotetext{
${ }^{1}$ Wobei die frühesten Spuren von Besiedlung auf dem Gebiet der späteren Stadt Rom schon im 3. und 2. Jt. v. Chr. nachgewiesen worden sind, wenn auch ohne topographischen und chronologischen Zusammenhang.
} 
Mit dem nächsten Kapitel (46 - 75) beginnt die Geschichte der römischen Republik, wie der Titel verkündet. Es handelt von den Gründern der Republik von P. Valerius Poplicola (48 - 51) bis L. Cornelius Scipio Scapula (72 - 75) und umfaßt die Zeit von etwa 560 bis ca. 270 v. Chr. Themenkästen wie jene zum römischen Triumph (50), zu den zwölf Tafeln (65) und zum Ausbau des römischen Straßensystems (73) bereichern diesen insgesamt zehn Biographien umfassenden Abschnitt des Werkes. Neben Poplicola und Scipio Scapula werden Horatius Cocles (51 - 53), Coriolan (53 - 55), T. Quinctius Capitolinus Barbatus (56 - 58), L. Quinctius Cincinnatus (58 60), der Decemvir Appius Claudius (61 - 64), M. Furius Camillus $(66$ - 69), Valerius Maximus Corvus (69/70) und Appius Claudius Caecus (70 - 72) beschrieben. Auch in diesem Kapitel ergibt sich die Schwierigkeit, sagenhafte Figuren von historisch greifbaren Personen unterscheiden zu müssen. Hier nun stellt der Autor seiner Beschreibung Coriolans explizit voran, daß dessen Existenz „noch unwahrscheinlicher“ sei ,als die der meisten anderen“ (54 oben), so daß eine Verwirrung des Lesers damit gebannt ist.

Im Verlauf der Republik wird die schriftliche Überlieferung dichter. M. gelingt nun, was im vorangegangenen Kapitel noch äußerst schwierig war: die Darstellung der Geschichte anhand der Lebensbeschreibungen einzelner herausragender Männer, welche teils gleichzeitig, teils zeitlich aufeinander folgend die Geschicke des Römischen Reiches bestimmen. In diesem Abschnitt über die mittlere Phase der römischen Republik (76 - 143) stehen die Feldherren der Punischen Kriege im Zentrum der Betrachtungen. Aber auch die Gegner, allen voran Hannibal, werden umrissen. Die Zahl der beschriebenen Persönlichkeiten steigt nun auf zwanzig an, darunter so berühmte Männer wie Q. Fabius Maximus, auch bekannt als „Cunctator“ (96 - 99), P. Cornelius Scipio Africanus (102-106), Cato der Censor (109 - 113) und die beiden Brüder und Volkstribunen Tiberius $(126-132)$ und Gaius Gracchus (133 - 138). Themenkästen wie jene zum frühen römischen Heer (80), der römischen Seefahrt (88) und $\mathrm{zu}$ dem karthagischen Feldherren Hannibal (95) illustrieren die wechselhaften Geschicke der römischen Konsuln in den punischen Kriegen, unterstützt durch ausführliche Karten zu den Kriegsschauplätzen (81, 92, 98, 106) und Feldzügen (96). Daneben liefert M. aber auch einen kurzen Abriß über den Einfluß der griechischen Kultur ab dem 2. Jh. v. Chr. (115) auf die Römer, worüber sich bekanntermaßen vor allem Cato der Censor echauffierte. Zudem bietet der Autor eine durch Zeichnungen unterstützte Anleitung zur korrekten Anlegung einer römischen Toga (132).

Mit dem Kapitel zur späten römischen Republik (144 - 231), welches insgesamt achtzehn Einzelbiographien enthält, tauchen die bekanntesten Namen der römischen Geschichte auf: C. Marius (149 - 159), L. Cornelius Sulla (164-171), Cn. Pompeius Magnus (181 - 190), C. Iulius Caesar (200 - 208), M. Tullius Cicero (211 - 215) und M. Antonius (216 - 222). Jede dieser Personen liefert, wie z.T. erst kürzlich erschienene Monographien belegen ${ }^{2}$, genügend Stoff für ein eigenständiges Werk. Dementsprechend müssen auch ihre Kurzbiographien mehr Seiten füllen als die Lebensbeschreibungen der vorangegangenen Personen in M.s Zusammenstellung. Hinzu kommen Ausführungen $\mathrm{zu}$ den Bundesgenossenkriegen (155) und zum Spartacusaufstand (177) sowie Beschreibungen eines typischen römischen Stadthauses (156/157), der römischen Vergnügungen in Theater und Arena (187-189)

\footnotetext{
${ }^{2} \mathrm{Zu}$ den neuesten Monographien gehören: W. Letzner, Lucius Cornelius Sulla. Versuch einer Biographie (2000); K. Christ, Sulla. Eine römische Karriere (2002); ders., Pompeius - der Feldherr Roms. Eine Biographie (2004); Werner Dahlheim, Julius Caesar (2005)
} 
und einer kurzen Skizzierung der Verhältnisse in Ägypten unter Kleopatra VI. (204/205).

Oktavian/Augustus (226 - 231) schließlich beendet erwartungsgemäß die lange Reihe der römischen Feldherren und Staatsmänner seit dem legendären Romulus und leitet über zu den römischen Kaisern, deren Viten bereits von etlichen antiken wie modernen - Historikern betrachtet und beschrieben worden sind.

M.s Buch ist nicht als neue Untersuchung zur römischen Ereignisgeschichte in der Tradition Bringmanns $\mathrm{zu}$ verstehen ${ }^{3}$ und bietet daher auch keine neuen Forschungsergebnisse. Es ist weniger für ein wissenschaftliches Fachpublikum geeignet, sondern dient vor allem als Überblicks- und Nachschlagewerk für alle Interessierten, die sich schnell über den einen oder anderen römischen Staatsmann oder Feldherren informieren möchten. Als solches ist es ein ungemein nützliches Werk.

${ }^{3}$ K. Bringmann, Geschichte der römischen Republik (2002) 